\title{
Development of a High-Speed Endoscopic OCT System and Its Application to Three-Dimensional Intravascular Imaging in Vivo
}

\author{
Han Saem Cho ${ }^{1}$, Sun-Joo Jang ${ }^{1,2}$, and Wang-Yuhl $\mathrm{Oh}^{1 \dagger}$ \\ ${ }^{1}$ Department of Mechanical Engineering, KAIST, Daejeon 305-701, Korea \\ ${ }^{2}$ Graduate School of Medical Science and Engineering, KAIST, Daejeon 305-701, Korea
}

(Received February 28, 2014; Revised manuscript March 27, 2014; Accepted April 4, 2014)

\begin{abstract}
Intravascular optical coherence tomography (OCT) enables imaging of the three-dimensional (3D) microstructure of a blood vessel wall. While 3D vascular visualization provides detailed information of the vessel wall and intraluminal structures, a longitudinal imaging pitch that is several times bigger than the imaging resolution of the system has limited true high-resolution 3D imaging. In this paper we demonstrate high-speed intravascular OCT in vivo, acquiring images at a rate of 350 frames per second. A 47-mm-long rabbit aorta was imaged in 3.7 seconds, after a short flush with contrast agent. The longitudinal imaging pitch was 34 micrometers, comparable to the transverse imaging resolution of the system. Three-dimensional volume rendering showed greatly enhanced visualization of tissue microstructure and stent struts, relative to what is provided by conventional intravascular imaging speeds.
\end{abstract}

Keywords: OCT, Endoscopic probe, Rotary junction, High-speed

OCIS codes: (170.4500) Optical coherence tomography; (170.2150) Endoscopic imaging; (170.3880) Medical and biological imaging

\section{고속 내시경적 OFDI 시스템 개발과 이를 이용한 3차원 생체 혈관 내부 이미징}

\author{
조한샘 ${ }^{1} \cdot$ 장선주 $^{1,2} \cdot$ 오왕열 $^{\dagger \dagger}$ \\ ${ }^{1}$ 한국과학기술원 기계공학과 \\ (우 305-701 대전시 유성구 대학로 291번지 \\ ${ }^{2}$ 한국과학기술원 의과학대학원 \\ (ㅇ) 305-701 대전시 유성구 대학로 291번지
}

(2014년 2월 28일 받음, 2014년 3월 27일 수정본 받음, 2014년 4월 4일 게재 확정)

혈관 내 OCT (optical coherence tomography) 는 혈관 벽 내부의 3차원적 미세구조를 영상화할 수 있어서 임상에서 각광을 받고 있다. 하지만 아직도 충분하지 못한 이미징 속도, 특히 내시경 프로브의 이미징 광 스캐닝 속도의 부족으로 혈관 길이 방향의 이미 징 간격이 실제 시스템의 광학적 해상도보다 5 배 이상 커서 혈관 종방향으로의 고해상도 이미징이 얻어지지 못하고 있는 상황이 다. 본 논문에서는 초당 350장의 혈관 벽 단층 영상을 제공하는 고속 혈관 내 OCT 시스템을 기술한다. 본 시스템과 내시경 장치를 이용하여 $47 \mathrm{~mm}$ 길이의 살아있는 토끼 대동맥을 3.7 초만에 $34 \mathrm{micron}$ 의 혈관 종방향 간격으로 얻는데 성공하였다. $34 \mathrm{micron}$ 의 종방향 간격은 실제 내시경의 그 방향 광학적 해상도와 비슷한 정도로서 3차원 모든 방향으로의 고해상도 이미징을 구현하였음을 보여준다. 얻어진 이미징 데이터의 3차원 영상 구현을 통해 혈관의 미세구조 및 이미징 전 삽입된 스텐트의 자세한 구조를 보였다.

Keywords: 광간섭단층촬영술, 내시경, 회전 접합부, 고속

OCIS codes: (170.4500) Optical coherence tomography; (170.2150) Endoscopic imaging; (170.3880) Medical and biological imaging communications

\section{I. 서 론}

혈관 내 광간섭단층촬영술(Intravascular optical coherence tomography)은 혈관 내에 내시경적 프로브(endoscopic probe) 를 삽입 하여 혈관 벽으로부터 후방산란된 빛의 간섭 정보를 이용하여 혈관벽의 깊이방향(axial)으로 5-10 $\mu \mathrm{m}$, 횡단방향

${ }^{\dagger}$ E-mail: woh1@kaist.ac.kr

Color versions of one or more of the figures in this paper are available online. 
(transverse)으로 20-40 $\mu \mathrm{m}$ 정도의 고해상도로 혈관벽의 횡단 면(cross sectional) 이미지를 획득하는 방법이다. ${ }^{[1]}$ 심장 질환 의 주요 병변 부위인 관상동맥 혈관 벽을 이미징 방법은 다 양하게 제시되었지만, 동맥경화반(atherosclerotic plaque)의 미세 구조를 이미징이 가능할만큼 충분한 해상도를 갖는 이 미징 방법은 현재까지 광간섭단층촬영술 뿐이다. ${ }^{[2]}$ 광간섭단 층촬영술을 이용하여 사람의 생체 내 관상동맥 이미징을 하 기 위해서는 빛이 혈액을 잘 투과하지 못하기 때문에 혈액을 일시적으로 조영제나 식염수 같은 대체물질로 플러싱(flushing) 하는 동안 진행한다. 하지만 관상동맥 혈관에 혈액이 오랫동 안 흐르지 않으면 근육이 괴사하고 심하면 대상자가 사망에 이를 수 있다. 이러한 제약 조건에서 느린 이미지 획득 시간 을 갖는 1세대 광간섭단층촬영술로는 혈관을 잠시 폐쇄(occlusion) 한 상태에서 대체물질로 플러싱하는 동안 오직 몇 장의 단편 적인 횡단면 이미지만을 획득할 수 있었다. OFDI(Optical frequency domain imaging) 방식과 같이 광 검출 민감도(optical detection sensitivity)가 뛰어난 2세대 광간섭단층촬영술이 개 발되면서 ${ }^{[3-6]}$ 혈관 폐쇄 없는 일시적인 플러싱으로도 살아있 는 사람의 관상동맥 혈관벽 이미지를 3차원적으로 표현할 수 있었다. ${ }^{[7]}$ 하지만 여전히 이미징 속도가 충분하지 않아서 혈관의 종방향 해상도가 횡단면 해상도에 대해 수 배 정도 좋지 않기 때문에 고해상도 3차원적 가시화(visualization)가 제대로 이루어지지 않았다. 이미징 속도는 시스템의 이미지 획득 속도(acquisition rate) 및 회전 스캐닝 부의 스캐닝 속도 에 의해 결정이 되는데, 현재까지 최고의 이미지 획득 속도 를 갖는 시스템이라도 스캐닝 부 속도가 이미징 속도의 한계 요인이 되었다. 현존 최고 속도 수준을 갖는 상용 시스템의 성능은 100 frames/s(MGH OFDI system(512 A-lines/frame) and C7-XR system(500 A-lines/frame), St. Jude Medical, Inc) ${ }^{[8,9]}$ 와 160 frames/s(Terumo OFDI system(512 A-lines/frame), Terumo Corp.) $)^{[10]}$ 등으로 혈관 종방향 해상도를 횡단면의 해상도에 준하도록 향상시키기에 이미징 속도가 충분하지 않다. 또한, 최근에 고속 마이크로 모터를 이용하여 ex vivo 상태의 관상 동맥 조직을 $3200 \mathrm{frames} / \mathrm{s}$ 의 고속 이미징 방법이 잠재력을 보여주며 발표되었지만 ${ }^{[11]}$ 생체에 적용하기 위해서는 내시경 적 프로브 끝 부분의 단단한 부분의 길이 및 프로브의 직경 크기 등의 생체 혈관 내 최적화 문제가 남아 있다.

본 논문에서는 350 frames/s(692 A-lines/frame)의 고속 생 체 내 2세대 광간섭단층촬영 이미징 시스템을 구현하였다. A-line 속도가 $242.8 \mathrm{kHz}$ 인 짧은 길이의 고리형 공진기 파장 가변 레이저(ring cavity type wavelength swept laser)와 최대 350 RPS(revolution per second)까지 내시경적 프로브를 회전 시키는 고속 회전 접합부(rotary junction) 및 고속에 적합한 내시경적 프로브를 개발하여 고속 시스템을 구현하였다. ${ }^{[12]}$ 시스템의 검증을 위해 조영제로 플러싱하는 동안 살아있는 뉴질랜드 화이트 종의 토끼 대동맥 $4.5 \mathrm{~cm}$ 를 3.7초만에 이미 징하였다. 혈관 종방향 프레임 간격은 횡단면 해상도에 견줄 만한 $34 \mu \mathrm{m}$ 였고, 3차원적 혈관 미세 구조 및 스텐트(stent)를 잘 구현함을 확인할 수 있었다.

\section{II. 고속 혈관 내 OFDI 시스템}

그림 1은 고속 혈관 내 OFDI 시스템의 구성도를 보여준다. 반도체 광 증폭기(semiconductor optical amplifier, SOA COVEGA BOA1130)와 광섬유 기반의 가변형 패브리-페로 필터(tunable Fabry-Perot filter, Lambdaquest)로 제작된 48 $\mathrm{cm}$ 정도의 짧은 길이 고리형 공진기 파장변환 레이저를 시 스템의 광원으로 사용하였다. 가변형 패브리-페로 필터는 공 명 주파수(resonance frequency)인 $60.7 \mathrm{kHz}$ 로 구동되며 필터 의 선형적 파장 변환 구간을 사용하고, 파장변환 속도를 높 이기 위해서 $25 \%$ 듀티비(duty cycle)로 레이저가 변조(modulation) 된다. 이 때 광섬유 지연선(fiber delay line)과 광 증폭기(booster optical amplifier, BOA COVEGA BOA1130)에 의해 공명 주 파수의 4 배 빠른 파장변환 속도를 갖게 된다. 이 레이저는 중심파장(center wavelength)이 $1290 \mathrm{~nm}$ 이고 $116 \mathrm{~nm}$ 의 가변 구간(tuning range)을 가지며 가변 반복률은 약 $242.8 \mathrm{kHz}$ 이 다. 또한, 레이저의 출력은 $62 \mathrm{~mW}$ 이고, 순간 선폭(instantaneous linewidth)은 $0.17 \mathrm{~nm}$ 이다. 레이저 출력의 $90 \%$ 는 샘 플암(sample arm)으로 전달되며 그 중 $99 \%$ 의 빛이 회전 접 합부로 전달되고, $1 \%$ 는 레이저의 비선형성(nonlinearity) 보 정 및 수치적 분산 보상(numerical dispersion compensation) 을 위해 사용된다. 기준암(reference arm)에 장착된 주파수 이동기(frequency shifter)는 $85 \mathrm{MHz}$ 로 구동되며 깊이 방향 정보의 겹침 현상(depth degeneracy)을 제거하기 위해 사용되 었다. ${ }^{[13]}$ 기준암의 $50 \%$ 의 빛은 광섬유 격자 센서(fiber Bragg grating)를 기반으로 한 트리거(trigger) 신호 생성에 사용된 다. 기준 거울로부터 반사되어 돌아온 빛은 샘플암의 혈관벽 으로부터 돌아온 빛과 편광다양 균형 검출부(polarizationdiverse, balanced detection part)에서 합쳐진다. 주파수 이동 기에 의한 분산을 보상하기 위해 AMTIR 크리스탈(Brimrose



FIG. 1. Schematic of high-speed intravascular second generation OCT system. SOA, semiconductor optical amplifier; TFPF, tunable Fabry-Perot filter; BS, 50/50 beam splitter cube; Coll, collimator; FDL, fiber delay line; BOA, booster optical amplifier; RJ, rotary junction; FBG, fiber Bragg grating; FS, frequency shifter; PBS, polarization beam splitter; crystal, AMTIR crystal for dispersion compensation from a frequency shifter. 
Inc., GeAsSe) 을 검출부 내 샘플암 입력 단자 전면에 장착 하였고, 기준암 입력단자 전면에는 선형 편광기(linear polarizer) 가 장착되어 기준암 출력이 고르도록 하였다. 두 개의 균형 검출기로 두 개의 직교하는 편광에 대해 각각 검출된 신호가 $340 \mathrm{MS} / \mathrm{s}$ 의 고속의 샘플링 속도(sampling rate)를 갖는 고해 상도의 디지타이저(digitizer, Signatec, PX-14400, 14bit)에 의 해 획득된다. 측정된 혈관 깊이 방향 해상도(axial resolution)는 공기 중에서 $9.2 \mu \mathrm{m}$ 이고 민감도(sensitivity)는 $102.5 \mathrm{~dB}$ 이다.

고속 회전 접합부는 시스템으로부터 오는 빛을 내시경적 프로브로 전달하는 역할과 동시에 전체 혈관벽의 이미지를 얻도록 스캐닝하기 위하여 내시경적 프로브를 회전시키는 역할을 한다. 그림 2는 (a)개발된 회전 접합부의 핵심부와 (b)회전 접합부 전부분을 보여주고 있다.

두 개의 광섬유 기반 시준기(fiber collimator)가 있고, 한 개의 시준기는 고정되어 있고, 한 개의 시준기는 빛의 진행 방향을 축으로 회전하는 구조이다. 두 시준기 사이에 자유공 간이 있어서 시준기가 회전하는 상태에 관계없이 빛이 전달 된다. 이 때 두 시준기에 홀더가 장착되어 있고, 고정된 홀더 와 회전하는 홀더는 두 개의 베어링으로 체결되어 고정된다. 회전부 부품을 소형화 설계를 하여 관성모멘트를 줄이고 안 정적인 회전을 하도록 하였다. 회전부는 타이밍 밸트를 통해 직류 서보 모터의 동력을 전달받아서 회전하게 된다. 이 때 회전 시준기는 360 도 회전 상태에 대해 $80 \%$ 의 빛 전달률 (transmission)을 갖도록 정렬 고정하였다. 회전 시준기의 광섬 유 커넥터는 SC/APC 어댑터가 연결되어 SC 타입의 내시경적 프로브가 장착될 수 있도록 구현되었다. 회전 접합부는 풀백 을 하기 위한 모터 구동 방식의 이동 스테이지에 장착되었다.
고속 회전 접합부로부터 전달받은 빛은 내시경적 프로브에 전달되고 프로브 끝 단에 위치한 한 쪽 면이 연마된 볼렌즈 (polished ball lens)에 의해 빛이 혈관벽에 조사된다. 그림 3 (a)는 내시경적 프로브의 핵심 부분을 (b)는 볼렌즈의 모습을 보여준다.

내시경적 프로브의 이미징 광학부(imaging optics)는 $1.65 \mathrm{~m}$ 길이에 해당하는 폴리미드(polyimide)로 코팅된 단일모드 광 섬유(single mode fiber)로 이루어져 있으며, 단일모드 광섬유 끝단에 짧은 길이의 코어리스 광섬유(coreless fiber)가 융착 된(splicing) 상태로 열을 이용해 볼렌즈를 구현하였다. 볼렌 즈의 곡률은 빔의 특성을 조절하기 때문에 광학 시뮬레이션 소프트웨어를 이용하여 설계요구 조건에 해당하는 볼렌즈의 최적 곡률(optimal curvature)을 바탕으로 볼렌즈를 제작하였 다. 볼렌즈의 곡률은 열을 가하는 시간 및 열이 가해지는 영 역 길이에 의해 결정된다. 코어리스 광섬유의 가열 시간 및 가열 영역 길이를 변화시킴에 따라 볼렌즈의 곡률이 정량적 으로 어떻게 변화하는지 기록 및 분석하였고, 이 분석 결과 를 토대로 원하는 최적 곡률을 얻기 위한 가열시간 및 가열 영역 길이를 결정할 수 있었다. 이 과정을 통해 얻게된 가열 시간 및 가열 영역 길이를 설정하여 최적 설계된 볼렌즈를 제작할 수 있었다. 또한, 제작된 볼렌즈의 곡률을 측정하여 내시경적 프로브의 성능을 평가하여 원하는 형태의 볼렌즈 로 제작되었는지 검토하였다. 내시경적 프로브는 측방 탐지 (side-looking)를 하기 위해서 볼렌즈 한 쪽 면을 연마(polishing) 하여 전반사 원리에 의해 혈관벽을 이미징할 수 있도록 구현 하였다. 제작된 이미징 광학부는 굽은 혈관 내에서도 회전력 을 잘 전달할 수 있도록 토크 코일(torque coil) 내에 삽입하



(a)

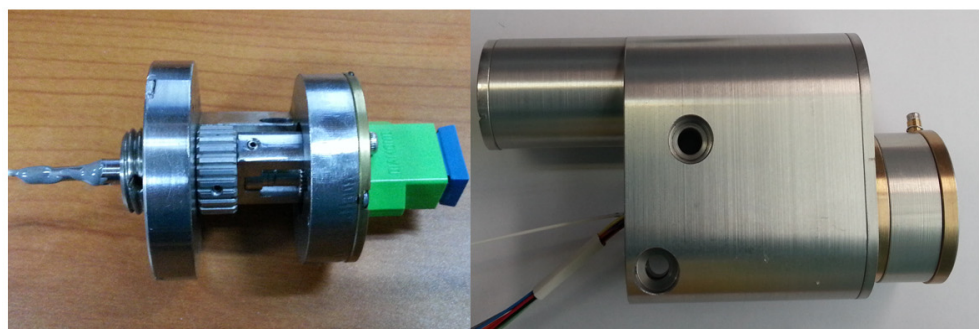

(b)

(c)

FIG. 2. (a) Schematic of core part of rotary junction, (b) Developed core part of rotary junction and (c) Fully assembled rotary junction.

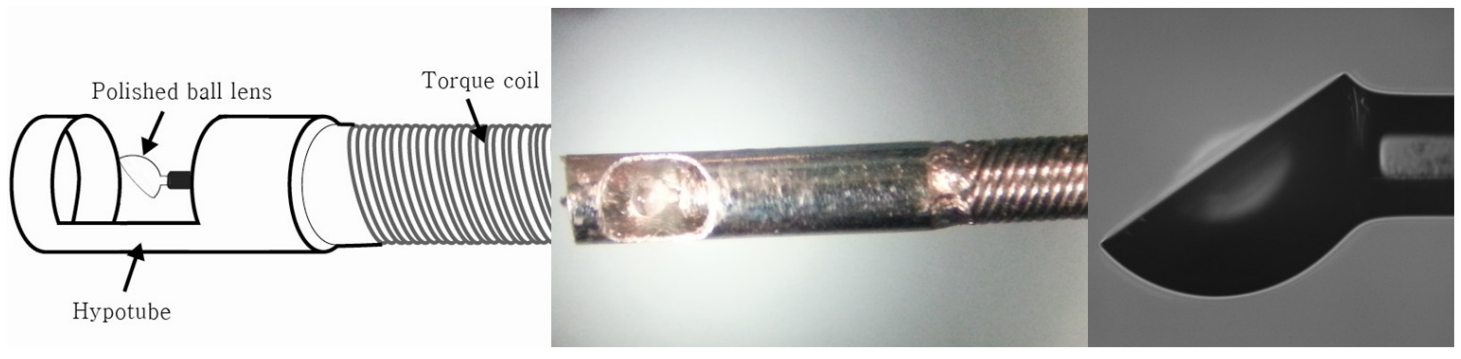

(a)

(b)

(c)

FIG. 3. (a) Schematic of core part of endoscopic OCT, (b) Developed core part of endoscopic OCT probe and (c) Polished ball lens. 


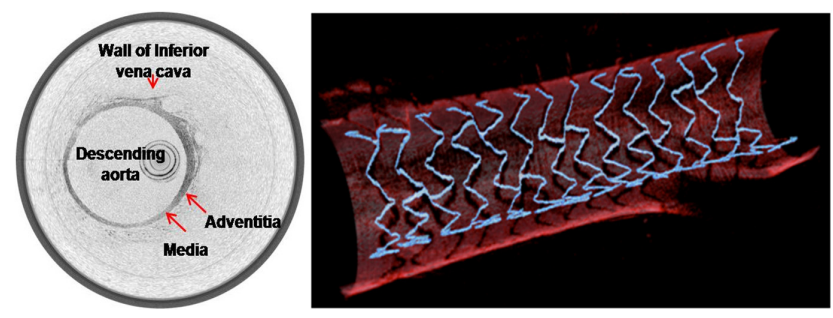

FIG. 4. (a)Transverse image of in vivo rabbit aorta and (b) 3D rendering OCT image of in vivo rabbit aorta.

여 접착하고, 이미징 광학부 끝 단에는 하이포튜브(hypotube) 를 사용하여 볼렌즈를 보호하면서 이미징할 수 있도록 구현 하였다. 토크코일 및 하이포튜브와 접착된 이미징 광학부는 외경이 $0.87 \mathrm{~mm}$ 인 외피(sheath)로 보호된다.

\section{III. 이미징 결과}

본 논문에서 제작된 관상동맥 혈관 내 이미징 시스템을 검 증하기 위해서 살아있는 토끼의 대동맥 이미징을 수행하였 다. 제작된 시스템의 혈관 종방향의 해상도가 향상된 것을 확인하기 위해서 토끼 대동맥 혈관 내에 스텐트를 삽입하여 이미징하였다. 그림 4(a)는 토끼 대동맥의 횡단면 이미지를 (b)는 이미징하여 도출된 혈관 종방향으로의 3 차원적 광간섭 단층촬영 이미지 랜더링(rendering) 결과이다. 토끼의 혈액을 혈관 조영제를 이용하여 플러싱하는 3.7초 동안 $350 \mathrm{frames} / \mathrm{s}$ 의 회전속도와 $12 \mathrm{~mm} / \mathrm{s}$ 의 풀백(pullback) 속도로 $45 \mathrm{~mm}$ 길 이의 혈관벽을 이미징한 결과를 보여준다. 이 때 혈관 종방 향의 해상도는 $34 \mu \mathrm{m}$ 이다. 랜더링 결과 스텐트의 스트러트 (strut)의 미세구조를 잘 확인할 수 있고 또 스트러트가 프레 임마다 매끄럽게 잘 이어지며 불연속 구간이 없는 것을 확인 할 수 있다. 또한, 실험 당시에 스텐트의 상태가 약간의 위치 이상 상태(malapposition)로 혈관벽까지 펼쳐지지 못했는데 혈관벽 위의 스트러트에 의한 그림자를 통해 확인할 수 있다.

\section{IV. 결 론}

본 논문에서는 제한된 이미징 시간에 기존 상용화 시스템 보다 혈관 종방향 해상도를 횡단면 해상도에 비등하도록 향 상시킨 관상동맥 이미징을 수행하기 위해 고속 프레임 속도 를 갖는 생체 혈관벽 이미징이 가능한 2 세대 광간섭단층촬 영 시스템을 개발하였다. 시스템의 고속화를 위하여 가변형 페브리-페로 기반의 고속 파장가변 레이저를 구현하여 2세대 광간섭단층촬영 시스템을 구성하였고, 현존하는 상용화 시스 템의 한계인 혈관벽 스캐닝 속도를 높이기 위해 고속으로 회 전하는 회전 접합부와 고속에 최적화 시킨 내시경적 프로브 를 제작하였다. 그 결과 최대 350 frames/s(692 A-lines/ frame) 까지 구동 가능한 시스템을 개발하였고, 이는 상용화 시스템 보다 약 2 배 빠른 수준이다. 시스템의 성능을 검증하기 위해 서 살아있는 토끼의 대동맥에 스텐트를 삽입하여 이미징을
수행하였고, 이 때 혈관 종방향의 해상도는 약 $34 \mu \mathrm{m}$ 로 횡 단면 해상도와 비등한 것을 확인할 수 있었다. 또한, 이미징 결과를 바탕으로 구현된 3차원적 랜더링 결과 스텐트와 혈 관벽의 미세구조 및 스텐트의 연결성이 매끄러운 것을 확인 할 수 있었다. 이 결과를 통해 본 2세대 광간섭단층촬영 시 스템이 혈관 플라그 분석, 관상동맥 중재술 평가 등과 같은 임상 연구에 적용될 수 있는 가능성을 확인하였다.

\section{감사의 글}

이 논문은 한국연구재단 중견연구자지원사업(도약과제, 2010-0017465), 글로벌프론티어사업(GFP/CISS-2012M3A6A 6054200) 및 IT융합 고급인력과정 지원사업(NIPA-2013-H040113-1007)의 지원으로 수행되었습니다.

\section{References}

1. I. K. Jang, B. E. Bouma, D. H. Kang, S. J. Park, S. W. Park, K. B. Seung, K. B. Choi, M. Shishkov, K. Schlendorf, E. Pomerantsev, S. L. Houser, H. T. Aretz, and G. J. Tearney, "Visualization of coronary atherosclerotic plaques in patients using optical coherence tomography: Comparison with intravascular ultrasound," J. Am. Coll, Cardiol. 39, 604-609 (2002).

2. H. Yabushita, B. E. Bouma, S. L. Houser, H. T. Aretz, I. K. Jang, K. H. Schlendorf, C. R. Kauffman, M. Shishkov, D. H. Kang, E. F. Halpern, and G. J. Tearney, "Characterization of human atherosclerosis by optical coherence tomography," Circulation 106, 1640-1645 (2002).

3. R. A. Leitgeb, C. K. Hitzenberger, and A. F. Fercher, "Performance of fourier domain vs. time domain optical coherence tomography," Opt. Express 11, 889-894 (2003).

4. M. A. Choma, M. V. Sarunic, C. Yang, and J. A. Izatt, "Sensitivity advantage of swept source and Fourier domain optical coherence tomography," Opt. Express 11, 2183-2189 (2003).

5. J. F. de Boer, B. Cense, B. H. Park, M. C. Pierce, G. J. Tearney, and B. E. Bouma, "Improved signal-to-noise ratio in spectral-domain compared with time-domain optical coherence tomography," Opt. Lett. 28, 2067-2069 (2003).

6. S. H. Yun, G. J. Tearney, J. F. de Boer, N. Iftima, and B. E. Bouma, "High-speed optical frequency-domain imaging," Opt. Express 11, 2953-2963 (2003).

7. S. H. Yun, G. J. Tearney, B. J. Vakoc, M. Shishkov, W. Y. Oh, A. E. Desjardins, M. J. Suter, R. C. Chan, J. A. Evans, I. K. Jang, N. S. Nishioka, J. F. de Boer, and B. E. Bouma, "Comprehensive volumetric optical microscopy in vivo," Nat. Med. 12, 1429-1433 (2006).

8. G. J. Tearney, S. Waxman, M. Shishkov, B. J. Vakoc, M. J. Suter, M. I. Freilich, A. E. Desjardins, W. Y. Oh, L. A. Bartlett, M. Rosenberg, and B. E. Bouma, "Threedimensional coronary artery microscopy by intracoronary 
optical frequency domain imaging," JACC Cardiovasc. Imag. 1, 752-761 (2008).

9. V. Farooq, B. D. Gogas, T. Okamura, J. H. Heo, M. Magro, J. Gomez-Lara, Y. Onuma, M. D. Radu, S. Brugaletta, and G. van Bochove, "Three-dimensional optical frequency domain imaging in conventional percutaneous coronary intervention: The potential for clinical application," Eur. Heart J. 34, 875-885 (2013).

10. T. Okamura, Y. Onuma, H. Garcia-Garcia, R. van Geuns, J. Wykrzykowska, C. Schultz, W. van der Giessen, J. Ligthart, E. Regar, and P. Serruys, "First-in-man evaluation of intravascular optical frequency domain imaging (OFDI) of Terumo: A comparison with intravascular ultrasound and quantitative coronary angiography," EuroIntervention 6,
1037-1045 (2011).

11. T. Wang, W. Wieser, G. Springeling, R. Beurskens, C. T. Lancee, T. Pfeiffer, A. F. W. van der Steen, R. Huber, and G. van Soest, "Intravascular optical coherence tomography imaging at 3200 frames per second," Opt. Lett. 38, 17151717 (2013).

12. H. S. Cho, S. J. Jang, K. Kim, A. V. Dan-Chin-Yu, M. Shishkov, B. E. Bouma, and W. Y. Oh, "High frame-rate intravascular optical frequency-domain imaging in vivo," Biomed. Opt. Express 5, 223-232 (2014).

13. S. H. Yun, G. J. Tearney, J. F. de Boer, and B. E. Bouma, "Removing the depth-degeneracy in optical frequency domain imaging with frequency shifting," Opt. Express 12, 4822-4828 (2004). 